\title{
1
}

\section{THE IMPORTANCE OF VETERANS HEALTH IN NURSING EDUCATION}

\author{
BRENDA ELLIOTT | KATIE A. CHARGUALAF | BARBARA PATTERSON
}

Never ... was so much owed by so many to so few.

Winston Churchill

\section{KEY TERMS}

military/veteran health issues

all volunteer force

veteran healthcare costs

military caregivers service-connected disability

joining forces

military/veteran cultural competency

\section{INTRODUCTION}

Decades of wars contribute to veterans with a wide range of visible and invisible wounds, temporary and permanent, which can influence their health over a lifetime. The health of veterans is a growing public health concern, yet nursing education is still in the early stages of integrating military/veteranrelated content into already content heavy curricula. Nurses at the bedside lack adequate knowledge to care for this population in a culturally sensitive manner. This chapter provides a brief overview of veterans in today's society, the major health issues challenging military service members, veterans and their families, and national initiatives that have been the catalyst for change to meet this population's needs. It also addresses the current status of veteran-related content in nursing education, why it is important, and where we need to go moving forward to ensure nurses are educated to deliver culturally sensitive, patient-centered care to this population.

\section{BACKGROUND}

The health of veterans is a growing public health concern, yet nursing education may still be in the early stages of integrating military/veteran-related content into already content heavy curricula. This chapter provides an overview of veterans in today's society, the war eras they fought, the major health issues

The complete reference list for this chapter appears in the digital version of the chapter, accessible at https:// connect.springerpub.com/content/book/978-0-8261-3597-1/chapter/ch01 
they face, as well as initiatives that have been the catalyst for change to meet this population's needs. To ensure a highly educated nursing workforce capable of meeting the healthcare needs of diverse populations such as military, veterans, and their families, educators must take action and continue to lead change to improve health outcomes for this group within society.

Addressing vulnerabilities of this population across generations, using a holistic and inclusive approach, requires concerted effort and institutional/organizational support. Nurses and healthcare providers need more education, and ideally exposure, to military service members, veterans, and their families to begin developing cultural sensitivity and competency. We know from the growing body of literature that current practicing nurses and healthcare providers generally feel unprepared to care for this population (Bonzanto et al., 2019; Richards et al., 2017; Tanielian et al., 2018; Vest et al., 2019). Thus, the optimal time to gain this knowledge and exposure is during prelicensure education.

According to the National Advisory Council on Nurse Education and Practice (2016), the nursing profession needs to examine the way in which nurses are educated. With an evolving and everchanging healthcare landscape, a shift from focusing on acute hospital care to population healthcare is needed. One population that needs greater focus are military service members, veterans, and their families (Villa et al., 2002). One barrier to obtaining exposure to this population is access. Therefore, the National Advisory Council on Nurse Education and Practice (2016) recommended that the U.S. Department of Veterans Affairs (VA) also examine ways to reduce the administrative burdens on schools and clinical sites so more opportunities for nursing students can be coordinated. Despite access barriers to VA facilities, opportunities exist to interact with this population with intentional efforts.

\section{VETERANS IN TODAY'S SOCIETY}

In American society, we have lived through a number of wars and conflicts over the past century. Millions of men and women have served our country in the Army, Air Force, Marines, Navy, and Coast Guard. Surviving still today, we have war veterans who have lived beyond the age of 100, eight decades since World War II ended. We also have veterans who do not live beyond 20. It seems safe to say that the majority of people in the country are proud of our military service members, veterans, and families as they have made many sacrifices for the privilege of our freedoms. Nevertheless, this pride has varied over the years, depending on political and societal support of certain wars and why we fight them. While not all service members serve or deploy during times of war, training alone puts them at risk for injury, disability, and death. Injuries, visible or invisible, as a result of training or conflict, have an impact on the health and well-being of service members, veterans, and their families. Often this impact can follow them into civilian life and continue over their lifetime, as health needs may not manifest until several decades beyond separation from military service or until research to connect symptoms to military service becomes available (Conard et al., 2015).

For nearly 20 years the United States has been engaged in global military activities, with the most recent war in Afghanistan, also known as Operation Enduring Freedom (OEF), officially ending December 31, 2014 (Defense Casualty Analysis System [DCAS], n.d.). Despite the end of OEF, troops remain present in Afghanistan to take part in a coalition mission to train, assist, and give counsel to Afghan National Defense and Security Forces called Operation Freedom's Sentinel (DCAS, n.d.). U.S. troops conduct operations to counter antiterrorism threats from the remnants of al Qaeda and to date have suffered 69 deaths and 369 wounded (DCAS, 2019). At present, thousands of military service members are deployed globally to provide security and conduct varying missions ("U.S. Military Operations," 2018). An estimated 1.3 million Americans are currently serving in the Armed Services and an additional 800,000 Americans are serving in Reserve and National Guard capacities (Defense Manpower Data Center, 2019). These numbers add to the more than 18 million veterans in the U.S. population in 2017 (VA, 2019a). Alaska, Maine, and Montana have the highest percentage of veterans (VA, 2019a). 
The estimated 18 million veterans living today represent service members who served during seven wars or conflicts and peace time. Table 1.1 illustrates the health-related service eras defined by the VA (2019b). In addition to those listed health associated risks, noise exposure and occupational hazards related to the job are a risk regardless of which era a service member or veteran has served. In addition, service members who served during the Cold War Era may have additional health-related issues if they were involved in one of the following projects: Projects 112 or Shipboard Hazard and Defense, The Atsugi Waste Incinerator, The Edgewood/Aberdeen Experiments, Camp Lejeune and Marine Corps Air Station New River, or Fort McClellan (VA, 2019b). Of note is that several wars and eras overlap, meaning that service members serving across multiple eras may have health risks associated with more than one time period. In addition, the number of reported risks has increased over the years and more service-related health concerns arise as research into these health risks continues.

\section{World War II}

Based on data from the National Center for Veterans Analysis and Statistics' population projections completed in 2016, an estimated 266,000 WWII (1939-1945) veterans would still be alive by the year 2020 and by 2045 that generation of veterans will be absent (VA, 2019c). Approximately 350 veterans of this era die every day (The National WWII Museum, n.d.). As our oldest living generation, it is important to reflect on the time period in which they served, as it helps to understand how they may now think and behave. For men born in the 1920s, serving in the military during WWII was a normative experience (Pruchno, 2016). These service members emerged from families who suffered hardships during the Great Depression, and they came out of war with many opportunities, including social and economic benefits (Spiro et al., 2016). WWII veterans were welcomed home by a country who was also deeply engaged in the war effort.

\section{Korean War}

Approximately 1.1 million Korean War (1950-1953) veterans are alive today, and it is estimated a few hundred could survive to the year 2045 (VA, 2019c). Often coined as the "forgotten war" due to it being sandwiched between a very popular WWII and a very unpopular Vietnam War, veterans of this era served in a war that, to date, still has not been officially resolved (National Veterans Foundation, 2015). Because they fought in the shadow of WWII, less attention was paid to this group of veterans. Yet most were drafted and served their country the same as all other men during the time between WWII and Vietnam. While the Korean War was publicly supported at the outset, its popularity faded with time. As cited by Villa et al. (2002) they are often "lumped" in with WWII veterans when analyzing health and well-being data between and among war eras, making it difficult to pinpoint some outcomes specific to this war era.

\section{Vietnam War}

Projections of Vietnam era veterans currently living is just over 6 million, with estimates of half a million still living by the year 2045 (VA, 2019c). The largest living cohort of male veterans served during this era (VA, 2019a). The Vietnam War (1961-1975) was markedly different for the American people as many protested the war and it was the first time in history that the war could be seen from uncensored media clips in any home (Elliott, 2015). It was a long, drawn out war spanning 14 years, more than double the duration of WWII and almost five times as long as the fighting period of the Korean War. The Vietnam War was less "traditional" compared to previous wars, as civilians engaged in guerilla or insurgency type warfare against U.S. troops, making the enemy difficult to identify (Villa et al., 2002). Deployment experiences changed from being gone for potentially several years as seen in previous wars, to returning home more periodically (Way et al., 2019). Advances in evacuating injured service members during combat greatly improved survivor rates, yet many veterans returning home did not 
TABLE 1.1 HEALTH-RELATED RISKS BY ERA SERVED

\begin{tabular}{|c|c|c|}
\hline WAR ERA & DATES & ASSOCIATED HEALTH RISKS \\
\hline World War II & $\begin{array}{l}\text { September 1, 1939-September 2, } \\
1945\end{array}$ & $\begin{array}{l}\text { lonizing radiation } \\
\text { Extreme cold } \\
\text { Mustard gas }\end{array}$ \\
\hline Korean War & June 25, 1950-July 27, 1953 & Extreme cold \\
\hline Vietnam War & $\begin{array}{l}\text { November 1, 1965-April 30, } \\
1975\end{array}$ & $\begin{array}{l}\text { Diseases related to Agent Orange } \\
\text { Diseases related to other herbicides } \\
\text { Hepatitis C } \\
\text { Liver fluke infection }\end{array}$ \\
\hline Cold War Era & 1945-1991 & $\begin{array}{l}\text { Radiation } \\
\text { Mustard gas } \\
\text { Herbicides (tests and storage) }\end{array}$ \\
\hline $\begin{array}{l}\text { Gulf War - Operation Desert } \\
\text { Shield and Desert Storm }\end{array}$ & August 2, 1990-present & $\begin{array}{l}\text { Extreme heat } \\
\text { Toxic embedded fragments } \\
\text { Infectious disease } \\
\text { Sand, dust, and particulates } \\
\text { Depleted uranium } \\
\text { Oil well fires } \\
\text { Chemical and biological weapons } \\
\text { CARC paint } \\
\text { Pesticides } \\
\text { Vaccinations } \\
\text { Pyridostigmine }\end{array}$ \\
\hline Iraq War - OIF and OND & $\begin{array}{l}\text { March 19, 2003-December 15, } \\
2011\end{array}$ & $\begin{array}{l}\text { Explosions } \\
\text { Extreme heat } \\
\text { Toxic embedded fragments } \\
\text { Infectious diseases } \\
\text { Rabies } \\
\text { Sand, dust, and particulates } \\
\text { Burn pit smoke } \\
\text { Depleted uranium } \\
\text { Sulfur fire } \\
\text { Chemical warfare agents } \\
\text { Chromium } \\
\text { Pesticides } \\
\text { Side effects of mefloquine }\end{array}$ \\
\hline OEF in Afghanistan & October 7, 2001-present & $\begin{array}{l}\text { Explosions } \\
\text { Extreme heat } \\
\text { Extreme cold } \\
\text { Toxic embedded fragments } \\
\text { Infectious diseases } \\
\text { Rabies } \\
\text { Sand, dust, and particulates } \\
\text { Burn pit smoke } \\
\text { Depleted uranium } \\
\text { Side effects of mefloquine }\end{array}$ \\
\hline
\end{tabular}

CARC, chemical agent resistant coating; OIF, Operation Iraqi Freedom; OND, Operation New Dawn; PB, pyridostigmine. SOURCE: From U.S. Department of Veterans Affairs. (2018). Veterans Benefits Administration annual benefits report: Fiscal year 2017. Retrieved September 27, 2019 from https://www.benefits.va.gov/REPORTS/abr/docs/2017_abr.pdf 
receive the same welcome as service members from previous wars. More women and minorities served their country during this war, compared to past wars, making Vietnam veterans all the more diverse (Spiro et al., 2016).

\section{Gulf War}

For the purposes of representing an ongoing era in history that continues to today, both Pre-9/11 and Post-9/11 will be included in this section. Post-9/11 includes Operation Iraqi Freedom (OIF), OEF, and Operation New Dawn (OND), which are collectively known as the War on Terror or Global War on Terrorism (GWOT; "A Timeline of the U.S.-Led War on Terror," 2019). According to the VA (2019b), 7.7 million from this era are now veterans. The largest cohort of women veterans served during this era (VA, 2019a). It is expected this group will peak in size around the year 2027 (VA, 2019b). By 2045, there will still be over 7 million veterans from these wars. Even if no additional wars break out in the next 25 years, millions of veterans will continue to need healthcare. The conflicts/wars that occurred during this time period were marked by a different type of battle rhythm, or rather a change in the daily routines and processes often seen during military operations (Spiro et al., 2016). Units and service members experienced multiple deployments, sometimes deploying as individuals and not with the unit in which they were assigned and completed training, with much less time between leaving the war zone and returning home. This complicated the return home for many service members.

\section{All Volunteer Force}

The all-volunteer force (AVF) was put into effect during the Vietnam era (Rostker, 2006). Up until that time, the military used a draft to fulfill military needs for most of the 20th century. This practice, generally accepted by American society, began to erode during the 1960s when discussions began to reevaluate military service (Rostker, 2006). Due to the changes brought on by the AVF, the military has become more of a professional military. The composition of the military has also changed. It is more diverse in regard to gender, race, and ethnicity (VA, 2019a), and less diverse in regard to socioeconomic status (Spiro et al., 2016). According to the VA (2019a), by the year 2040 the overall veteran population is expected to drop from 18.6 million to 12.9 million, while the proportion of veterans who are minorities will increase from $23 \%$ to $34 \%$. Since the AVF was introduced in 1973, more Reserve and National Guard service members are called upon to augment Active Duty forces, which contributes to even more variation in socioeconomic challenges as these groups are generally older and have more family responsibilities compared to their Active Duty counterparts (Spiro et al., 2016).

According to Lanaras (2016), today's military veterans who served under the AVF may struggle more overall compared to those who served under the draft. Having an AVF is not likely the cause of this shift as challenges with reintegration, loss of camaraderie, or even dealing with physical or mental injuries are not so vastly different among war cohorts. Before the AVF, service members represented people from all backgrounds and from all over the United States (Lanaras, 2016). People in every community across the country knew someone who served. Today, military service members come disproportionately from the South and have close family members who served (Lanaras, 2016). In addition, the closure of military bases over the past two decades has reduced the number of active installations in urban and northeast regions of the United States, shifting more military personnel to rural and southern regions. This results in a large portion of people in the United States not having direct contact with the military or veterans. Lanaras (2016) suggests that veterans who served under the draft were forced to reintegrate, but for today's veterans that process has perhaps changed allowing more of them to be self-isolating, which can lead to greater problems.

Way et al. (2019) postulate that as a result of the switch to an AVF, a higher concentration of service members are entering the military with histories of adverse childhood experiences. This could further 
explain the variance in today's veterans struggling more after their service ends. Men with a history of service during the AVF era had a higher prevalence of adverse childhood experiences in all 11 categories inventoried, which lends support to the notion that entering military service for men served as an escape from dysfunctional home lives (Blosnich et al., 2014). While women of the same AVF era had higher prevalence in just four of 11 categories inventoried, the researchers postulate their entry into the military is more to improve socioeconomic opportunities. Their reasoning for this is that the military is comprised mostly of men (Blosnich et al., 2014). Of concern is the associated risk of suicide to adverse childhood experiences. Blosnich et al. (2014) reminded us that people who experience adverse childhood experiences can and do go on to live healthy lives, and that those who enlist in the military do it for positive reasons. To avoid unintentionally elevating stigma toward those who have had adverse childhood events, Blosnich et al. (2014) encouraged balanced messaging that demonstrates support. Therefore, it continues to be important when making comparisons of war eras to understand factors that may make veterans quite different with respect to healthcare needs.

\section{HEALTH ISSUES FACING THE MILITARY/VETERAN POPULATION}

Military service members are exposed to a variety of hazards, placing them at risk for long-term health problems that range from training injuries to something highly recognizable such as exposure to Agent Orange from the Vietnam era. With the fastest growing cohort of veterans being those who served Post-9/11, more focus will be placed on this sub-group within the larger veteran population. This section includes a discussion of the phenomenon of the healthy solider effect, allostatic load, and a summary of the most common service-related disabilities.

\section{Healthy Soldier Effect}

There exists a phenomenon, the healthy soldier effect, which refers to those who served in the military as healthier compared to other populations (McLaughlin et al., 2008). It is proposed that initial screening criteria to determine a person's "fit" for service, physical training, and standards maintained during military service, and access to healthcare while serving may protect the mortality of military service members (McLaughlin et al., 2008). In their systematic review of the literature, the researchers determined military personnel display a healthy soldier effect ranging from $10 \%$ to $25 \%$, depending on the cause of death and the period of follow up. Waller and McGuire (2011) proposed that the healthy soldier effect changes over time and may vary depending on the cohorts being compared and by the cause of death. In contrast, Bollinger et al. (2015) conducted a study of OIF/OEF/OND veterans and found this cohort of veterans had either equivalent or higher than expected mortality compared to the general U.S. population. This suggests that the healthy soldier effect may be eroding. Further, a study conducted by Cranston et al. (2017) found that protective health effects of military fitness standards in a group of Air Force personnel are reduced shortly after retirement (6-8 years), with the prevalence rates of metabolic syndrome shifting toward that of the U.S. population in that time frame. Further, Cranston et al. (2017) suggested that healthcare providers educate newly retired veterans of this effect so that preventive measures can be initiated and risks reduced.

\section{Allostatic Load}

Allostatic load is a term used to describe the cumulative effects of acute and chronic stress on the body (McEwen et al., 2012). How often a person is exposed to factors that influence allostatic load or the rate at which it accumulates is individual. However, it is postulated that the outcomes resulting from allostatic load can be physiological, psychological, or psychosocial (McEwen et al., 2012). Chronic and repeated stressors, often experienced by military personnel, may be combined by acute stress incidents and, over time, result in a shift from adaptive to maladaptive functioning. This maladaptive functioning 
can lead to negative health consequences such as cardiovascular, metabolic, immune, and autoimmune disorders. Military deployments are one such stressor that helps support and explain the effect of allostatic load (McEwen et al., 2012).

Through complex processes of homeostasis and allostasis, our bodies adapt to stress or challenges (McEwen et al., 2012). When the body's mediating responses are chronically triggered it can lead to disease, resulting in allostatic load that is manifested by anger, frustration, fatigue, and feeling out of control. Subsequently, this state of allostatic load can lead to disruptions in sleep, anxiety, and other poor coping mechanisms such as drinking, smoking, or overeating (McEwen et al., 2012). This may help explain the increase in sleep issues facing Post-9/11 veterans (Caldwell et al., 2019). While this model is just one of many to help explain the health effects of stress on the body, it is important to recognize the repeated and continuous stress on military service members and their families so that action can be taken to mitigate stress and decrease potential adverse health outcomes.

\section{Service-Connected Disabilities}

Military service members participate in physically demanding activities on a routine basis, placing them at risk for a multitude of musculoskeletal injuries. The most prevalent service-connected disabilities include chronic long-term hearing and orthopedic problems (VA, 2018). Table 1.2 displays the most prevalent service-connected disabilities of all compensated recipients. According to a VA annual report, GWOT veterans account for 59\% of compensated disabilities (VA, 2018). In addition, 53,770 women and 541,016 men are compensated as 100\% disabled.

When specifically examining GWOT veterans, sleep apnea syndromes (obstructive, central, mixed) replace paralysis of the sciatic nerve (Table 1.2), among the top service-connected disabilities (VA, 2018). Caldwell et al. (2019) examined the association of insomnia and sleep apnea with deployment and combat exposure in the entire population of U.S. Army soldiers from 1997 to 2011 and found a major increase in both disorders between 2003 and 2011. Caldwell et al. (2019) found that deployment more than doubled the risk of developing insomnia or obstructive sleep apnea (OSA) compared to non-deployed counterparts. Combat exposure also increased the risk for insomnia (Caldwell et al., 2019). The researchers determined five conditions more than double or triple the risk of insomnia, which were (a) sleep-related movement disorder, (b) posttraumatic stress disorder (PTSD), (c) anxiety,

TABLE 1.2 MOST PREVALENT SERVICE-CONNECTED DISABILITIES OF ALL COMPENSATED RECIPIENTS

\begin{tabular}{|l|l|l|}
\hline DISABILITY & MALE & FEMALE \\
\hline Tinnitus & $1,654,756$ & 92,860 \\
\hline Hearing loss & $1,101,363$ & 21,048 \\
\hline PTSD & 866,005 & 81,549 \\
\hline Scars, general & 805,971 & 111,568 \\
\hline Lumbosacral or cervical strain & 763,632 & 144,594 \\
\hline Limitation of flexion, knee & 745,186 & 119,921 \\
\hline Paralysis of the sciatic nerve & 609,375 & 53,226 \\
\hline Limitation of the motion of the ankle & 498,027 & 68,622 \\
\hline Migraine & 365,472 & 121,465 \\
\hline Degenerative arthritis of the spine & 409,666 & 57,000 \\
\hline
\end{tabular}

PTSD, posttraumatic stress disorder.

SOURCE: From U.S. Department of Veterans Affairs. (2018). Veterans Benefits Administration annual benefits report: Fiscal year 2017. Retrieved September 27, 2019 from https://www.benefits.va.gov/REPORTS/abr/docs/2017_abr.pdf 
TABLE 1.3 HEALTH RANKINGS OF THOSE WHO SERVED COMPARED TO CIVILIANS

\begin{tabular}{|l|l|l|l|l|l|}
\hline $\begin{array}{l}\text { CHRONIC } \\
\text { CONDITION }\end{array}$ & SERVED (\%) & $\begin{array}{l}\text { NOT } \\
\text { SERVED (\%) }\end{array}$ & $\begin{array}{l}\text { UNHEALTHY } \\
\text { BEHAVIORS }\end{array}$ & SERVED (\%) & $\begin{array}{l}\text { NOT } \\
\text { SERVED (\%) }\end{array}$ \\
\hline Arthritis & 24.7 & 22.8 & Smoking & 19.9 & 16.6 \\
\hline Cancer & 10.9 & 9.8 & $\begin{array}{l}\text { Smokeless } \\
\text { tobacco }\end{array}$ & 8.7 & 3.5 \\
\hline $\begin{array}{l}\text { Cardiovascular } \\
\text { disease }\end{array}$ & 9.8 & 7.2 & $\begin{array}{l}\text { Excessive } \\
\text { drinking }\end{array}$ & 21.4 & 18.6 \\
\hline
\end{tabular}

SOURCE: Data from United Health Group. (2018). New data - American's health ranking: Health of those who have served report. Retrieved September 27, 2019 from https://www.unitedhealthgroup.com/newsroom/posts/2018-1112-ahr-report-those-who-served.html

(d) adjustment reaction, and (e) acute reaction to stress. The presence of hypertension, gastroesophageal reflux disease, diabetes, PTSD, and overweight/obesity were among the top five conditions that more than doubled the risk of developing OSA. While the researchers attribute some portion of the results related to increased OSA to be related to increased incidence of overweight/obesity in the Army in the past decade, they concluded that more research is necessary to understand the underlying cause. Of concern for nurses is assessing veterans for sleep disturbances, as a number of physical and mental health problems can develop from insufficient sleep.

\section{Brief Comparisons to Civilian Counterparts}

Data support that those who have served report high rates of unhealthy behaviors (United Health Group, 2018). Veterans also report better overall health compared to those who never served. Yet, in actuality, veterans face higher rates of some chronic diseases compared to those who have never served (United Health Group, 2018). Table 1.3 illustrates these data. Data suggest veterans also suffer higher rates of depression, anxiety, and mental distress (United Health Group, 2018). In contrast to the negative health effects of service, veterans demonstrate strengths over their civilian counterparts in several measured areas. According to the report, veterans fare better in preventive health measures such as dental visits, flu vaccination, and colorectal cancer screening (United Health Group, 2018). Veterans also had less (8.7\%) unmet medical needs due to cost compared to civilians (14.1\%).

Aside from chronic disease, one pressing issue that has raised alarm is the rate of suicide plaguing veterans. From 2008 to 2017 the number of veteran suicides exceeded 6,000 per year, averaging about 16 per day (VA, 2019d). An estimated 2.5 suicides per day in 2017 were former Reserve or National Guard members who were never activated. Compared to non-veteran adult women, veteran women had a 2.2 times higher rate of suicide in 2017 (VA, 2019d). The rate of suicide for men was 1.3 times higher in veterans compared to non-veteran adult men in the same year.

\section{DEPARTMENT OF VETERANS AFFAIRS}

Military service members, their families, and military retirees and their eligible family members and survivors receive medical care through the Military Health System (MHS), which is the universal health system of the Department of Defense (DoD, n.d.). There are an estimated 600 clinics and over 50 military hospitals, both in the United States and at various overseas locations, which serve this population. In addition, TRICARE ${ }^{\mathrm{TM}}$ insurance provides coverage for contracted civilian care when necessary. For service members and their families assigned to areas where no MHS facility is available, there is a higher rate of engagement in civilian healthcare systems.

The VA (2019e) is comprised of three major administrations: (a) Veterans Health Administration (VHA), (b) Veterans Benefits Administration (VBA), and (c) National Cemetery Administration. Across 
the three administrations, military service members, veterans, and their families may be eligible for a variety of benefits that range from educational assistance, healthcare, or home loan support, to name just a few (VA, 2019f). It is key to understand that not every person who has served in the military is eligible for benefits. Eligibility for each of the benefits varies, is subject to change over time, and can be complex to comprehend even for those who serve. For example, as new research reveals a link between Agent Orange exposure and a specific disease, eligibility for healthcare is also expanded to those affected despite the amount of time that has passed since the Vietnam War. However, not all veterans may be aware of these changes and are therefore not receiving entitled benefits. Due to the complexity of eligibility, healthcare providers are encouraged to visit the VA website (www.va.gov) and contact a representative.

The VHA boosts a wealth of information through their public health sector, which is accessible online (www.publichealth.va.gov). The public, including healthcare providers, can learn a great deal about military and veterans' health ranging from military exposures to chemicals and noise to mental health. The VA develops evidence-based public policy, conducts research, and educates not only those who work within the VA system but also provides resources for healthcare providers who may encounter veterans outside the VA. Within the public health pages one can also find information on current research studies and registries for those who may have been exposed or deployed during a time that has potential risk for long-term effects such as the VA airborne hazards and open burn pit registry (www.publichealth.va.gov/exposures/burnpits/registry.asp).

\section{U.S. Department of Veterans Affairs' Priorities}

Based on the 2018-2024 Strategic Plan (VA, 2019g), the priorities of the VA include customer service, implementation of the MISSION Act, improvements in electronic health records, business systems transformation, and suicide prevention. The MISSION Act permits veterans greater access to healthcare in and outside the VA, expands caregiver benefits, and improves the VA's ability to offer the best medical providers to deliver care (VA, 2019h). Of significant importance to nursing is the national crisis to address suicide among military and veteran populations, with potential interaction occurring more frequently in civilian settings. According to Barr et al. (2019), being non-honorably discharged from military service may place veterans at higher risk for poor behavioral and mental health outcomes compared to those honorably discharged. Results of their study showed higher mean scores for non-honorably discharged veterans across all study variables, which included PTSD, depression, alcohol misuse, physical disability, somatic symptoms, and suicide risk (Barr et al., 2019).

The VA has become increasingly interested in the population health indicators that take into account the social determinants of health (SDOH), to assist them in achieving their commitment to both medical and non-medical needs of patients (Duan-Porter et al., 2018; Hatef et al., 2019). The changing demographics of the military include more minorities and women (VA, 2019a), either marginalized or vulnerable populations historically, so this focus is necessary to improve quality healthcare for this population and reduce further health disparities. This notion is further supported in a study examining the impact of SDOH on medical conditions among transgender veterans (Blosnich et al., 2016), another historically marginalized group. The research team found that social determinants of transgender veterans were strongly associated with medical conditions and that documentation of SDOH can help providers identify and address these factors as part of the plan of care (Blosnich et al., 2016).

A mere 6.1 million veterans utilized VA healthcare in 2017 (VA, 2019a). This leaves approximately $60 \%$ of today's veterans seeking care in civilian settings, supporting the need for all healthcare providers to have foundational knowledge of veterans' unique needs. Historically, quality and access to VA care has been under close scrutiny. Some veterans may have a positive experience with the VA system, while others may not, leading to distrust of the VA system. Therefore, nurses in all settings should be aware of the "newest VA reform measures and philosophy as it impacts patient care and resources" (Carlson, 2016, p. 7). Whether one practices at the bedside, teaches healthcare providers in 
the classroom, or has nursing students who are veterans, it is imperative that the momentum continues to self-educate and be able to advocate regardless of the practice setting.

\section{IMPACT OF SERVICE ON HEALTH OVER A LIFETIME}

Military service can have both a positive and a negative impact on a person's health. There are a number of factors that influence health, making it complex to generalize. One major factor that contributes to a veterans' health is how they appraise their military service, which can be conceptualized in three ways: overall military experience, wartime experience, and combat experience (Settersten et al., 2012; Spiro et al., 2016). Spiro et al. (2016) proposed an interdisciplinary model that takes into account life span and life course. The five principles outlined in their model are: (a) the effects of military service are lifelong; (b) the effects of service are multi-dimensional, affecting multiple domains of life, including health and well-being; (c) military service leads to both gains and losses; (d) the effects of military service are experienced within a matrix of social relationships that can protect veterans or create risk for them over time; and (e) these effects occur within and are affected by sociohistorical context. Their model (Figure 1.1) takes into consideration pre-military characteristics of a person, entry into the military, military experiences, post-military pathways, and then later-life outcomes. In addition,

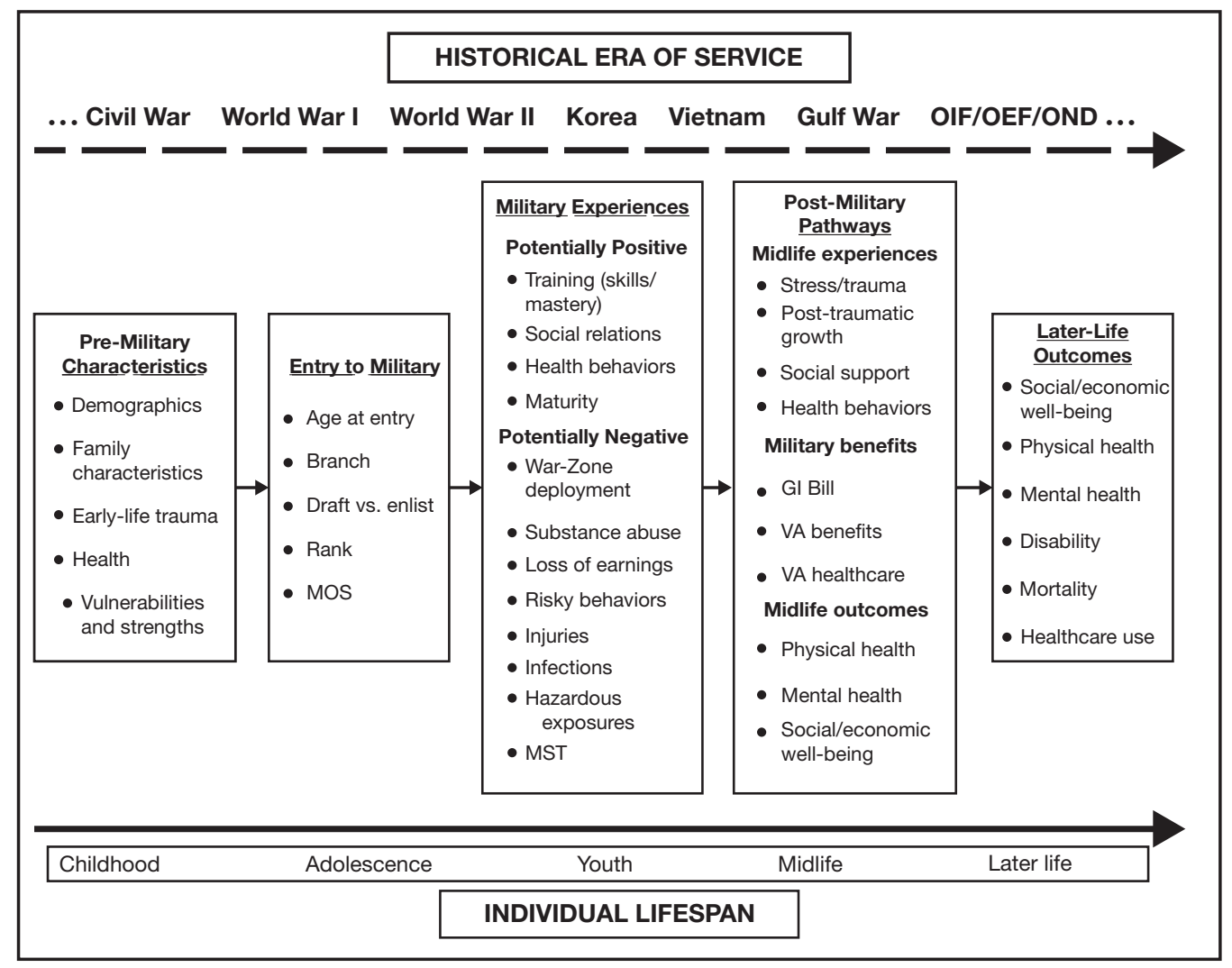

FIGURE 1.1 Long-term outcomes of military service.

MOS, military occupational specialty; MST, military sexual trauma; OEF, Operation Enduring Freedom; OIF, Operation Iraqi Freedom; OND, Operation New Dawn; VA, U.S. Department of Veterans. Affairs.

SOURCE: From Spiro, A., Settersten, R.A., \& Aldwin, C.M. (2016). Long-term outcomes of military service in aging and the life course: A positive re-envisioning. The Gerontologist, $56(1), 5-13$, by permission of Oxford University Press. 
physical health, mental health, and socioeconomic domains are suggested to measure outcomes (Spiro et al., 2016). With most military service members entering service between the ages of 18 and 22, early adulthood, their experiences during service occur during a critical point in life (Pruchno, 2016). Spiro et al. (2016) proposed that "rather than asking whether military service has long-term effects, the more appropriate questions are, for whom does military service have long-term positive and/or negative effects, in which domains, and why?" (p. 7).

For the majority of people who enter the military they do so as they enter into young adulthood, defined by Erickson as ages 18 to 35 ("Erikson's Stages of Development," 2019). With parental consent, youth can join the military at age 17 ("Are You Eligible to Join the Military," 2019). During this developmental stage, coined Intimacy and Solidarity versus Isolation, people typically seek companionship, deep intimacy, and satisfying relationships. Some may get married and start families, which are major life changes. If people in this stage do not establish close relationships with a spouse or friends, isolation may occur ("Erikson's Stages of Development," 2019). For those serving in the military, camaraderie has been identified as a common thing people miss when they leave military service (Callahan, 2015). Therefore, it can serve as a protective factor while serving but may be problematic once separated from service. Frequent relocation and deployments during the early years of relationships, marriage, and raising young children, can place significant strain on service members and their families making them vulnerable to emotional and physical health problems. No single factor determines this. However, it can also create strong bonds and resiliency.

Middle-aged adulthood ranges from age 35 to age 55 to 65 ("Erikson's Stages of Development," 2019). Although age limits vary among service branches, a person can also join the military during middle age, with the Air Force allowing people to enter as late as age 39 ("Are You Eligible to Join the Military," 2019). Generativity versus Self-Absorption or Stagnation, the terms used to describe this stage, is a time when people are most focused on a career/work and family. People strive to make a difference in society (generativity), with a common fear of meaninglessness if they do not ("Erikson's Stages of Development," 2019). Major life changes can start to occur during this stage, such as children leaving the home or changing careers. For those who stay in the military until retirement (20 years of active duty), potentially longer if serving the National Guard or Reserves, middle adulthood is the time when they are taking off the uniform and stepping back into civilian life. This transition and reintegration can prove challenging after living and working in the military culture for that length of time.

According to Erikson's developmental stages of life ("Erikson's Stages of Development," 2019), persons in late adulthood (age 55-65 to death) fall into a stage of Integrity versus Despair. As a stage of reflection, individuals may look back on life with a sense of fulfillment and contentment that they lived a life of meaning and their contribution to society was valuable (integrity). On the contrary, individuals may also look back on their life experiences with a sense of failure and struggle, unable to see what purpose their life served (despair). As veterans age and face typical stressors all older adults face such as illness, declining functional ability, and losses, they may simultaneously engage for the first time or reengage with prior military and war time memories in an attempt to find meaning and build coherence (Davison et al., 2016). Davison et al. (2016) call this process later-adulthood trauma reengagement (LATR), postulating that during this dynamic stage of life veterans may be trying to adapt and get "unstuck" from past traumatic experiences so they may find meaning and build coherence with life. Through life review, reminiscing, and facing the issues they are experiencing, veterans may experience delayed-onset posttraumatic growth. The LATR process may help them reconcile past experiences, leading to integrity and not despair, ultimately improving satisfaction with life.

Seligowski et al. (2012) studied the correlates of life satisfaction among aging veterans and found that variables representing personal resources (social support, sense of mastery, and positive appraisal of military experience) appeared to have the strongest relationship to satisfaction with life for older veterans. Both physical and mental health were significantly and positively linked to life satisfaction in their study. Seligowski et al. (2012) suggested that veterans who possessed the belief they have power to influence and effectively manage their own personal domain later in life may be a protective factor against late life 
distress. Further, Lee et al. (2017) found that veterans of the Korean War experienced traumatic memories and suffering of veteran stereotypes, as well as an increased personal strength and appreciation of life from their service. One participant in their study suggested that even after 60 years, time did little to ease the pain of the traumatic experiences, supporting that older veterans may have unresolved inner conflicts as they age and reach end of life (EOL). Korean War veterans in this study identified membership in veteran associations as a foundational bridge for veterans to support each other (Lee et al., 2017). Active problem solving, planning, and use of non-avoidant coping skills were assessed as strengths in the study group. The researchers stated "nurses and other helping professionals need to be aware of the veteran's strengths and support systems" so they can provide patient-centered care (Lee et al., 2017, p. 235).

\section{Palliative Care and End of Life Considerations}

End of life (EOL) can be a difficult time for any human being and their loved ones. Being a veteran and facing EOL may bring with it a number of mental and physical concerns above and beyond what one might anticipate for non-veterans (Elliott, 2017). Progressive illness or a life-limiting prognosis can often magnify psychosocial issues for veterans, compromising their capacity to face the dying process (Antoni et al., 2012). Acknowledging military service is essential and is especially important when caring for a veteran at EOL (Gabriel et al., 2015). Yet, many healthcare providers may not be assessing for veteran status or may lack resources and expertise in addressing issues facing veterans (Antoni et al., 2012). In addition, healthcare providers may feel uncertain what to do with information they obtain (Maiocco et al., 2018), or may not feel comfortable evaluating military-related causes of distress at EOL (Way et al., 2019). Respecting and honoring the veteran and their family for the service and sacrifice to our country can aid in building trust and rapport during this stressful time. Understanding the manner in which a veteran may process guilt from the past, handle symptoms of PTSD that may surface due to the stress of dying, or even differences in the way they cope with pain at the EOL are key pieces to providing veteran-centered care (Elliott, 2017; Way et al., 2019).

Difficulties and symptom burden faced by veterans at EOL can stem from spiritual conflicts or survivor's guilt (Elliott, 2017), as well as adverse childhood experiences, military sexual trauma, PTSD, or moral injury (Way et al., 2019). With a growing number of veterans who have had adverse childhood experiences, "more and more veterans may find their social support to be lacking or find that relationships may be severed as they reach EOL" (Way et al., 2019, p. 712). Therefore, it is critical for nurses and healthcare providers to understand the veteran experience, evaluate their resources and supports, and be cognizant that for those who do have families and caregivers, they may also need support during this challenging time. Although not all veterans want to share their stories, those that do could be carefully guided using gradual reminiscing (Elliott, 2017; Young et al., 2018) or storytelling (Carlson, 2016).

Over the past two decades the VA has made great strides in improving palliative and EOL care for veterans through a variety of initiatives and programs, both internally and externally (Way et al., 2019). One external partnership between the VA and the National Hospice and Palliative Care Organization, which has grown and evolved, is the We Honor Veterans (WHV) program (www.wehonorveterans. org). The WHV program, through education and resources, engages community agencies such as home care and hospice, as well as long-term care and assisted living facilities, to recognize the unique needs of veterans, their families, and caregivers. Expanding from WHV are programs such as the Hospice-Veteran Partnership, the Veteran Community Partnership, the Veteran-to-Veteran Partnership, and the No Veteran Dies Alone program (Way et al., 2019). Collectively, these programs have reached more veterans than could otherwise be reached by VA services alone, especially in rural areas.

\section{SOCIETAL IMPLICATIONS}

Over decades of wars, the military has been a main contributor in advancing life-saving measures. With the GWOT, tourniquet use, and better trained medics and soldiers (buddy-care and self-care), 
TABLE 1.4 NUMBER OF DISABILITIES PER VETERAN BY WAR ERA

\begin{tabular}{|l|l|l|l|l|l|l|}
\hline & WW II & $\begin{array}{l}\text { KOREAN } \\
\text { WAR }\end{array}$ & $\begin{array}{l}\text { VIETNAM } \\
\text { ERA }\end{array}$ & $\begin{array}{l}\text { GULF WAR } \\
\text { ERA }\end{array}$ & $\begin{array}{l}\text { PEACETIME } \\
\text { PERIODS }\end{array}$ & TOTAL \\
\hline Disabilities & 166,391 & 286,679 & $5,345,987$ & $14,889,302$ & $2,528,136$ & $23,216,495$ \\
\hline $\begin{array}{l}\text { Average no. of } \\
\text { disabilities per } \\
\text { veteran }\end{array}$ & 2.41 & 2.45 & 3.83 & 6.73 & 3.34 & 5.10 \\
\hline
\end{tabular}

SOURCE: From U.S. Department of Veterans Affairs. (2018). Veterans Benefits Administration annual benefits report: Fiscal year 2017. Retrieved September 27, 2019 from https://www.benefits.va.gov/REPORTS/abr/docs/2017_abr.pdf

the result has been a higher survival of amputees (Baker, 2014). Changes in fluid resuscitation and blood volume restoration protocols, coupled with the use of mobile forward surgical teams, allowed for quicker stabilization and safe mobilization to higher echelons of care. Critical Care Air Transport Teams enabled the highest acuity of patients to be transported to medical centers for more definitive care. Further, advances in information technology improved how well essential information followed patients from one stage of care to the next so that providers could administer the very best care (Baker, 2014). The result was more wounded service members surviving injuries that would have killed them in prior wars. Cumulatively, Gulf War veterans have approximately 14.8 million service connected disabilities (Table 1.4), with the average number of disabilities per veteran at 6.7 (VA, 2018). Subsequently, the future health, social, and economic impact on healthcare resources will be significant.

\section{Cost of Caring for Veterans}

An estimated $61 \%$ of GWOT service members are veterans, leaving 39\% still in the military (Baker, 2014). Researchers project that in the next 30 to 40 years, the care needs of the most recent war veterans will escalate and have likened it to a tidal wave coming in (Baker, 2014; Geiling et al., 2012). Healthcare for these veterans will shift from the DoD or MHS healthcare system, to the VHA System, and eventually private sectors. The long-term care needs (Geiling et al., 2012), coupled with extensive rehabilitation and restorative care (Baker, 2014), have demanded civilian healthcare providers be prepared to treat this population. Additionally, there is an increased demand placed on caregivers. Geiling et al. (2012) projected that billions of dollars would be not only spent providing this care, but delivering better, more effective care to restore veterans to optimal physical and mental health, and ultimately reducing some of the future financial costs.

\section{Impact on Families and Caregivers}

Referring to the collateral damage of war, Baker (2014) stated, "Another huge impact on society for which there is no metric is the tragic effect of this fiasco on veterans' families" (p. 352). Spouses, children, parents, and siblings can be affected by deployments, injury, or death of loved ones; development of mental health issues, change in economic or social status, or substance abuse (Arceneaux et al., 2019). This risk for collateral damage is on top of the stressors a military lifestyle places on service members and families, which requires multiple relocations, changing schools for children, spouses having to find new employment, and changing social supports. This is often all at a distance from immediate family. In addition, children of military caregivers may be at risk to suffer more social isolation, mental health challenges, and poorer quality of life (Elizabeth Dole Foundation, 2018). Parents who are military caregivers may find meeting the needs of their children difficult when balancing caregiving and household tasks.

In a secondary analysis of 2010 National Survey of Veterans data, Schnittker (2019) examined the health spillover effect (the effect of the experience of one person on the health of another) among 
military spouses. Data revealed that spouses of active duty service members report worse health compared to spouses living with a veteran. Data also supported that the impact of military service experiences on a spouse may extend long-term, beyond the initial transition to civilian life (Schnittker, 2019). The researcher reported that the magnitude of the effects of being married to an active duty service member "are as large as the widowhood effect, which is, in turn, as large as caring for a veteran spouse with a service disability" (Schnittker, 2019, p. 71). Of interest is that lower self-rated health was not explained by active conflict, presence of young children in the home, or high unemployment of spouses, which are typically major stressors for military families. While more research is needed to understand the effects of military service on spouses, this study brings to light the potential impact on the health of close family members.

Based on data from a 2014 Rand report (Ramchand et al., 2014), there are an estimated 5.5 million military caregivers in the United States. Almost 20\% are caring for Post-9/11 veterans, who do not resemble military caregivers from previous war eras. According to Tanielian et al. (2013), "the appeal of military service to future generations is based upon our nation's commitment to support our service members, veterans, and military families" (p. 2). Safeguarding that adequate care is available for veterans is a critical piece of this obligation. The burden of this care falls largely on America's military caregivers, many of whom prioritize their veterans' health and well-being over and above their own (Tanielian et al., 2013). Caregivers may experience a great risk of disease or other negative health outcomes such as coronary heart disease, hypertension, compromised immune function, and reduced sleep as a result of the physical strain from being a caregiver (Tanielian et al., 2013).

Military caregivers are typically younger, reside with the individual they are caring for, care for individuals with complex injuries and comorbidities, and navigate changes in eligibility benefits in a complex healthcare system, making them different from civilian caregivers (Tanielian et al., 2013). They experience a great deal of emotional stress associated with caregiving, unduly suffering from mental health problems. Klippel and Sullivan (2018) postulate that caregivers of veterans with PTSD may experience more stressors if behavioral and emotional symptoms are not regulated. Maintaining open and honest communication may be the best way to enhance relationship satisfaction for caregivers at risk of experiencing caregiver burden. This is especially true in the presence of comorbid dementia, which can complicate PTSD symptoms and requires more care (Klippel \& Sullivan, 2018). New evidence suggests that veterans who have experienced a traumatic brain injury (TBI) are at increased risk for developing dementia (Peterson et al., 2019). This further complicates the potential long-term care and costs considering that the number of veterans who experienced a TBI during deployment is estimated between $10 \%$ and $20 \%$ as reported in several studies conducted since 2008 (Peterson et al., 2019). Compared to previous war eras, those deployed during the Gulf War era are at higher risk for developing chronic traumatic encephalopathy due to repeated blast exposure, which is also of concern for caregivers long-term (Peterson et al., 2019).

In a qualitative study on health-related quality of life in caregivers of individuals with military-related TBI, researchers identified four domains in which caregivers spent the most time discussing their concerns (Carlozzi et al., 2016). Those domains included social health, emotional health, physical/ medical health, and cognitive health. Within the social health domain, caregivers voiced difficulties with finances as a result of giving up work, changes in social roles between the person with the TBI and others, including close social systems such as extended family. Caregivers voiced uncertainty with how hard to push the person they cared for who used to be an independent person, switching from spouse to caregiver, reevaluating priorities and future plans, and loss of friends. The emotional domain concerns were caregiver strain/burden, feelings of loss, anger, and anxiety, and depression. In this domain, caregivers shared how military culture influences one to maintain a strong appearance, even when things are not going so well (Carlozzi et al., 2016). Thus, caregivers felt like they were constantly minding their behaviors, and the behaviors of others, as to avoid noticeably upsetting the service member. The last two domains were less commonly spoken about yet are important to consider. Caregivers 
voiced difficulty keeping up with their own healthcare needs, how the injury negatively affected their sexual health, and how sleep difficulties coupled with caregiving responsibilities left them constantly fatigued. Cognitive concerns related primarily to feelings of not being "sharp" anymore, as if they too had a TBI (by proxy). Overall, military caregivers in this study often experienced caregiver hypervigilance and emotional suppression of anger related to ease of access to the VA or financial services, further differentiating them from their civilian counterparts (Carlozzi et al., 2016).

The Program of Comprehensive Assistance for Family Caregivers (PCAFC) was established in 2011 to support caregivers of Post-9/11 era veterans who required assistance with activities of daily living, or supervision resulting from residual effects of injuries sustained while in the line of duty (Van Houtven et al., 2019). The comprehensive program requires caregivers to complete a training curriculum, including topics such as caregiving skills, caregiver self-care, and managing challenging behaviors. Participants must also meet other eligibility requirements. Van Houtven et al. (2019) examined the early impact of the PCAFC on veteran healthcare utilization and cost and found that enrollment in the program led to increased utilization of VA outpatient care, specialty care, and mental healthcare. Despite not having an impact on reducing acute emergency department usage, the increased short-term utilization of other services could lead to positive long-term health outcomes for vulnerable veteran patients.

\section{NATIONAL INITIATIVES FOCUSED ON EDUCATING NURSES}

The efforts of local, state, and federal agencies in response to the needs of veterans, particularly in the past decade with the Post-9/11 era veterans growing in numbers, are vast. Currently, over 7,000 U.S.-based non-profit organizations are helping military service members, veterans, and their families ("Nonprofit Organizations for Veterans," 2019). This section focuses on two key initiatives that were launched as a catalyst to address the healthcare needs of service members, veterans, and their families.

\section{Veterans Affairs Nursing Academy}

As a result of the growing numbers of veterans requiring combat-related medical care at the onset of the Iraq and then Afghanistan wars as well as the demand for nurses within the VHA health system, the VA (2017) launched the Veterans Affairs Nursing Academy (VANA). The purpose of the VANA was to expand learning opportunities for nursing students at VA facilities and fund additional faculty at partnership schools so more undergraduate students could be accepted, with the intent of increasing recruitment and retention of VA nurses. The 5-year, \$40 million program launched in 2007 and to date there are 18 partnerships between the VA and schools of nursing in the United States. In 2014 the program transitioned to a non-funded program (Carlson, 2016).

There are a few publications describing the implementation of VANA partnerships (Harper et al., 2015) and their effectiveness (Dobalian et al., 2014; Miltner et al., 2015). Perhaps of greater importance and relevance are the lessons learned from the implementation of partnerships and how those lessons can be utilized by anyone working with and caring for military and veteran populations. Within the first 18 months of joining the pilot program, researchers visited each VANA site at least once to gather data on program implementation to determine what elements were critical for partnership effectiveness (Dobalian et al., 2014). The researchers identified both positive and negative indicators of a successful or unsuccessful launch based on the program goals, which were the initial program inputs and implementation activities and outputs for increasing faculty positions, increasing student enrollment, implementing curricular innovations, increasing recruitment and retention, and promoting collaboration. Through the analysis of their data, five themes or key factors, were extracted (Dobalian et al., 2014). The first critical factor in enabling partnerships to succeed was teamwork or collaboration between organizations. A second factor related to blending different cultures and integrating activities across differing organizational practices and constraints. Third, the time required to recruit nurses to take faculty roles, while expanding 
student enrollment and scheduling clinical and didactic courses, needed to be realistic. The need to plan more strategically was identified as the fourth factor focused on expectations beyond adding faculty and increasing student enrollment. At the time of this research study there was an economic downturn, making the demand for nurses tempered (Dobalian et al., 2014). Therefore, the last factor related to the importance of partnerships being long-term commitments, whereby short-term changes in supply and demand for nurses should not impact the solidity of the relationship.

As nursing education moves forward with curricular changes, considering partnerships that afford student nurses the opportunity for exposure to military service members, veterans, and their families is essential. Harper et al. (2015) reported that through their VA partnership the school of nursing was able to expand its program in a number of ways, enriching student experiences with veteran-specific simulations, an elective course on veteran healthcare, and creation of a veteran-friendly culture. Clinical faculty should require students to inquire about military or veteran status during their initial assessment to maximize their opportunity to engage with this population. Through various publications, nursing programs report on the initial logistical challenges of gaining access to Veterans Affairs Medical Centers (VAMC), but persistence seems to be beneficial. For those who do not have nearby access to these facilities, there are many options to locate and engage veterans outside of the VAMC.

\section{Joining Forces}

The Joining Forces campaign was spearheaded and launched in 2011 by then first lady Michelle Obama and Dr. Jill Biden (White House Archives, n.d.). The overall purpose of the campaign was to mobilize Americans to support service members, veterans, and their families through employment, education, and wellness. The initiative had six main goals (Box 1.1). On April 11, 2012, the Office of the First Lady

\section{BOX 1.1}

\section{JOINING FORCES INITIATIVES}

Educating America's future nurses to care for our nation's veterans, service members, and their families facing posttraumatic stress disorder, traumatic brain injury, depression, and other clinical issues

Enriching nursing education to ensure that current and future nurses are trained in the unique clinical challenges and best practices associated with caring for military service members, veterans, and their families

Integrating content that addresses the unique health and wellness challenges of our nation's service members, veterans, and their families into nursing curricula

Sharing teaching resources and applying best practices in the care of service members, veterans, and their families

Growing the body of knowledge leading to improvements in healthcare and wellness for our service members, veterans, and their families

Joining with others to further strengthen the supportive community of nurses, institutions, and healthcare providers dedicated to improving the health of service members, veterans, and their families.

SOURCE: From White House Archives. (2012). America's nurses Join Forces with the first lady and Dr. Biden to support veterans and military families. Retrieved May 23, 2019 from https://obamawhitehouse.archives.gov/the-press-office/ 2012/04/11/americas-nurses-join-forces-first-lady-and-dr-biden-support-veterans-and 
released a statement that " 3 million nurses, through 150 nursing organizations and 500 nursing schools will be educated on PTSD and TBI in the coming years" (White House Archives, 2012, para. 1). In collaboration with the VA and DoD, the American Nurses Association (ANA), American Academy of Nurse Practitioners, American Association of Colleges of Nursing (AACN), and the National League for Nursing (NLN) led the charge to secure commitment from other nursing organizations to educate future and current nurses in military and veteran-specific healthcare issues they might face in their respective practice settings.

In response to the Joining Forces initiative, the American Academy of Nursing (AAN) created a Military and Veterans Health Expert Panel in 2011, responsible to develop policy recommendations and facilitate outreach to healthcare providers (AAN, 2015). In 2013, the panel launched their "Have you ever served in the military $?^{\text {Tnom }}$ campaign in 10 states, sparking change in nursing practice to ensure vital military service information was obtained (ANA, n.d.). With quality of care as a driver, this campaign reached all 50 states by April of 2015. The NLN (2019) responded to the call to Join Forces by developing resources titled Advancing Care Excellence for Veterans. These teaching resources provide faculty with unfolding case studies, simulations, teaching strategies, and other resources to aid in teaching nursing students at all levels of veteran-specific care.

As one of the leading organizations for nursing education, the AACN answered the call for action from the White House and sought the pledge of member schools to join in support of educating students about the military and veteran population. By 2014, just 2 years after the launch of Joining Forces, approximately 660 schools pledged support (Elliott \& Patterson, 2017). The AACN (2019a) created the Enhancing Veteran's Care Faculty Tool Kit as a resource for faculty to implement curricular elements that focus on this population. In addition, the AACN also partnered with the City of Hope to create End-of-Life Nursing Education Consortium (ELNEC) for Veterans to enhance palliative and EOL care nationally for this population (AACN, 2019b). A veteran-specific curriculum was created and six nationally held train-the-trainer programs were offered to 745 nurses and interdisciplinary healthcare providers representing over 200 VA facilities and community programs, such as hospice and home care agencies (AACN, 2019b).

Elliott and Patterson (2017) conducted a study to determine how schools of nursing who pledged to support Joining Forces incorporated military and veteran health content into their curricula, as well as barriers and facilitators to this process. Within the first 3 years of the pledge, findings suggested variation of implementation with some schools/colleges of nursing exceeding the initiative goals to some still in the process of figuring it out. The majority of respondents felt incorporating this content was important, but lack of time and a content-laden curriculum were identified as common barriers (Elliott \& Patterson, 2017). Based on the data, approximately $75 \%$ of respondents indicated they had achieved the first goal (Box 1.1). The remaining five goals ranged between $43 \%$ and $56 \%$ achieved. Nurse educators have an ethical responsibility to teach students culturally sensitive care. Making the pledge was only the first step to change. To date, we are not aware of any further research that examines the long-term impact of the Joining Forces pledge. However, it remains the charge for nurse educators to advance curricular changes.

\section{Military/Veteran Friendly}

"Military Friendly is the standard that measures an organization's commitment, effort and success in creating sustainable and meaningful opportunity for the military community" ("What Does Military Friendly Mean," 2019, para. 2). More and more colleges and universities, as well as various organizations, have sought this designation as a way to stand out among the crowd in terms of commitment and excellence to supporting and serving people in the military (active duty, National Guard, Reserve), veterans, and their spouses. Healthcare organizations can also receive this designation. Thus, they are setting a standard of care and improving the outcomes and lives of veterans. 


\section{CURRENT STATUS OF NURSING EDUCATION AND PRACTICE}

At the time of this writing, it is still unclear exactly what nurses and healthcare providers know about caring for military service members, veterans, and their families. What they need to know is more apparent with a moderate number of publications available in professional journals. Efforts from professional organizations appear steadfast. Many gaps in understanding the difference between education and practice remain. From 2010 until present day the number of publications across disciplines related to the care of military service members, veterans, and their families has escalated. Within nursing publications, authors have focused primarily on what currently practicing nurses need to know in civilian settings or exemplars of curricular changes to enhance nursing education. Table 1.5 illustrates an array of publications, although we acknowledge the list may not be exhaustive and some publications fall into more than one group. The following section summarizes the current status of nursing education and practice literature to date, with a more focused discussion on practice-related research. Section III of this book examines nursing education subject matter in more detail.

\section{Nursing Education}

To gauge what students may be exposed to, the authors conducted an informal appraisal of readily available nursing textbooks to evaluate presence of content related to military service members, veterans, and their families. Although it was not an exhaustive or systematic process, we found nursing texts currently in print largely fail to acknowledge the full spectrum of veteran healthcare needs. In fact, a limited number of undergraduate psychiatric nursing textbooks draw attention to veteran care needs and are exclusively linked to PTSD and suicide content. These examples fail to capture the scope and breadth of military and veteran health-related knowledge needed by nurses in practice today and for the future.

A number of authors have evaluated and published competencies for students, nurses, and nurse faculty (Carlson, 2016; McMillan et al., 2017; Moss et al., 2015). Collectively, these publications illustrate the essential knowledge, skills, and attitudes vital to care for or teach military/veteran-centric content. Above all, military culture is the most widely addressed competency when engaging with and caring for this population. Simulation or unfolding case studies are often highlighted as effective teaching strategies. Some schools of nursing have created stand-alone courses focusing on veteran-centered health, while others have illustrated ways in which content can be integrated through various courses or clinical experiences such as Community Health, Mental Health, and Medical-Surgical nursing. Various organizations have collected and packaged toolkits and resources for education and professional development. Yet, educators must know they are available and how to best utilize them. At the advanced practice level, two universities to our knowledge have developed post-bachelors and specialty programs focused on the care of military and veteran populations for nurses and healthcare providers to prepare already-practicing providers.

\section{Nursing Practice}

For nurses currently in practice, a number of resources and publications are available. The essential message in these publications is the importance of screening and assessing patients for military or veteran status. Second is knowing what do to with the essential information that is gathered. Research conducted to evaluate non-VA employed or civilian nurses' experiences or comfort level in caring for military and veteran patients and their families is limited. It appears that more is being published regarding the importance of understanding military, veterans, and families' healthcare needs than reports of action taken or interventions trialed in clinical areas to improve care. This may be due to the fact that nurses may be learning what is important, yet translation to practice is its infancy. Table 1.6 highlights currently available empirically based reports. 
TABLE 1.5 SELECT NURSING PUBLICATIONS RELATED TO MILITARY AND VETERAN HEALTH (2012-2020)

\begin{tabular}{|c|c|c|}
\hline FOCUS OF PUBLICATION & YEAR & CITATION (AUTHOR) \\
\hline Nursing care of veterans & $\begin{array}{l}2013 \\
2013 \\
2014 \\
2015 \\
2015 \\
2015 \\
2015 \\
2016 \\
2017 \\
2017 \\
2017 \\
2018 \\
2018 \\
2019 \\
2019 \\
\end{array}$ & $\begin{array}{l}\text { Johnson et al. } \\
\text { Miltner et al. } \\
\text { Stanton } \\
\text { Conard et al. } \\
\text { Counts et al. } \\
\text { Fullwood } \\
\text { Elliott } \\
\text { Conard et al. } \\
\text { Elliott } \\
\text { Mohler and Sankey-Deemer } \\
\text { Waszak and Holmes } \\
\text { Elliott } \\
\text { Young et al. } \\
\text { Elliott } \\
\text { Conard and Armstrong }\end{array}$ \\
\hline $\begin{array}{l}\text { Recommendations for educational } \\
\text { preparation, including competencies }\end{array}$ & $\begin{array}{l}2013 \\
2015 \\
2015 \\
2015 \\
2016 \\
2016 \\
2017 \\
2017 \\
2017 \\
2017 \\
2020\end{array}$ & $\begin{array}{l}\text { Allen et al. } \\
\text { Linn et al. } \\
\text { Moss et al. } \\
\text { Olenick et al. } \\
\text { Carlson } \\
\text { Cooper et al. } \\
\text { Champlin et al. } \\
\text { Elliott and Patterson } \\
\text { Finnegan et al. } \\
\text { McMillan et al. } \\
\text { Finnegan et al. }\end{array}$ \\
\hline Exemplars of curricular changes & $\begin{array}{l}2015 \\
2015 \\
2015 \\
2017 \\
2018 \\
2018\end{array}$ & $\begin{array}{l}\text { Keavney } \\
\text { Jones and Breen } \\
\text { Morrison-Beedy et al. } \\
\text { Magpantay-Monroe } \\
\text { Rossiter et al. } \\
\text { Crary }\end{array}$ \\
\hline $\begin{array}{l}\text { Teaching and learning strategies for } \\
\text { veteran-related content }\end{array}$ & $\begin{array}{l}2012 \\
2012 \\
2013 \\
2016 \\
2017 \\
2017 \\
2018 \\
2018 \\
2019 \\
\end{array}$ & $\begin{array}{l}\text { Anthony et al. } \\
\text { Harmer and Huffman } \\
\text { Beckford and Ellis } \\
\text { McKenzie et al. } \\
\text { Champlin and Kunkel } \\
\text { Kaplan et al. } \\
\text { Magpantay-Monroe } \\
\text { Vessey et al. } \\
\text { Regan et al. }\end{array}$ \\
\hline Professional development of nurses or faculty & $\begin{array}{l}2016 \\
2017 \\
2019 \\
2019 \\
2018\end{array}$ & $\begin{array}{l}\text { Merkle et al. } \\
\text { Erickson-Hurt et al. } \\
\text { Chargualaf } \\
\text { Gibbs et al. } \\
\text { Maiocco et al. }\end{array}$ \\
\hline Military cultural competence & $\begin{array}{l}2013 \\
2014 \\
2015 \\
2018 \\
2018 \\
2019 \\
2019 \\
\end{array}$ & $\begin{array}{l}\text { Convoy and Westphal } \\
\text { Koenig et al. } \\
\text { Westphal and Convoy } \\
\text { Brommelsiek et al. } \\
\text { Kautzmann and Lancaster } \\
\text { Bonzanto et al. } \\
\text { Vest et al. }\end{array}$ \\
\hline Military caregivers & 2017 & Conard et al. \\
\hline
\end{tabular}


TABLE 1.6 EMPIRICAL EVIDENCE INFORMING NURSING PRACTICE

\begin{tabular}{|l|l|l|l|}
\hline AUTHOR & YEAR & TYPE & FOCUS AREA \\
\hline Bonzanto et al. & 2019 & $\begin{array}{l}\text { Prospective quantitative } \\
\text { survey }\end{array}$ & $\begin{array}{l}\text { Examined the capacity of RNs working } \\
\text { in non-VA hospitals to deliver culturally } \\
\text { competent care to military, veterans, and } \\
\text { their families }\end{array}$ \\
\hline Elliott & 2018 & Quantitative descriptive & $\begin{array}{l}\text { Assessed home care nurses' knowledge, } \\
\text { comfort, and confidence caring for } \\
\text { veterans }\end{array}$ \\
\hline Elliott & 2019 & Qualitative descriptive & $\begin{array}{l}\text { Examined home care nurses' experiences } \\
\text { caring for veterans }\end{array}$ \\
\hline Maiocco et al. & 2018 & Multimethod descriptive & $\begin{array}{l}\text { Assessed how nurses are caring for } \\
\text { veterans and the challenges they face in } \\
\text { delivery of that care }\end{array}$ \\
\hline Merkle et al. & 2016 & Quality improvement & $\begin{array}{l}\text { Designed, implemented, and evaluated a } \\
\text { screening process to identify veterans in } \\
\text { the emergency department }\end{array}$ \\
\hline $\begin{array}{l}\text { Mohler and Sankey- } \\
\text { Deemer }\end{array}$ & 2017 & $\begin{array}{l}\text { Quantitative descriptive, } \\
\text { cross-sectional }\end{array}$ & $\begin{array}{l}\text { Assessed screening practices for military } \\
\text { service and PTSD of healthcare providers } \\
\text { in a primary care setting }\end{array}$ \\
\hline Vest et al. & 2019 & Qualitative descriptive & $\begin{array}{l}\text { Assessed barriers to care and perceptions } \\
\text { of what tools are most valuable in } \\
\text { developing cultural competency }\end{array}$ \\
\hline
\end{tabular}

PTSD, posttraumatic stress disorder; VA, U.S. Department of Veterans Affairs.

Veterans, even those eligible for care at a VA, can and may seek care elsewhere (VA, 2019a). Merkle et al. (2016) designed and implemented a screening process to identify veterans during emergency department visits at a civilian hospital. The authors reported embedding a mandatory screening question "Have you ever served in the military?" in the electronic medical record. The authors noted that screening for TRICARE ${ }^{\mathrm{TM}}$ insurance, a practice of some providers, was insufficient and many veterans were either not identified or misidentified (Merkle et al., 2016). Department staff developed a resource guide for veteran patients to be given at encounters in the emergency department. Through their change process and asking about military or veteran status, more veterans were identified and provided a resource guide as part of their discharge instructions. No other outcomes were measured and the authors recommended further required education and training beyond this initial intervention.

Mohler and Sankey-Deemer (2017) conducted a cross-sectional study examining the screening practices of non-VA primary care providers in rural central and western Pennsylvania. Their sample included physicians, physician assistants (PAs), and nurse practitioners (NPs). The researchers aimed to determine first if providers screen for military service and, second, if they then screen for PTSD. Although the sample size was small $(N=50)$, the results do provide a basis for beginning to understand the work that is yet to be done in educating civilian providers. Results indicated $88 \%$ of subjects had no education related to the healthcare needs of veterans. Only $8 \%$ of providers responded they screen all patients for military service, $40 \%$ responded they never screen, leaving the majority (52\%) who screen somewhere in between. A mere 10\% screened all or most patients for PTSD, after identifying patients as veterans.

According to Maiocco et al. (2018), the state of West Virginia issued a mandate in 2014 of 2 hours of annual education related to mental health issues in veterans. This was a result of the increase in suicides within this population in West Virginia, which was significantly higher than the overall national rate, as well as a high percent of veterans seeking care outside the VA. At the time of the study, West Virginia 
was the only state requiring this education. Continuing education (CE) was provided between the years of 2015 and 2016 (Maiocco et al., 2018). Upon completion of the CE, the authors conducted a survey using open-ended questions to gain understanding of the impact of $\mathrm{CE}$ on nurses. The results of their study revealed that only $16 \%$ of nurses consistently asked about military status and of those only $6 \%$ document status upon admission (Maiocco et al., 2018). In addition, 85\% did not know where to access this information if it were documented, $86 \%$ were unaware of hospital resources and services to assist nurses in caring for veterans, and $83 \%$ did not know how to refer a patient to the VA. From the open-ended questions, three themes emerged: uncertainty related to delivery of care, uncertainty related to inexperience talking to veterans, and uncertainty related to potential for violence.

The researchers reported stopping the study early due to reports of violence from veterans toward nurses found in the survey data (Maiocco et al., 2018). The primary investigator alerted risk management of the unsafe practice environment and steps were taken to ensure documentation of military/ veteran status. Based on the results and despite education, 'the 'Have you ever served campaign?' has generated mindfulness about military culture, but translation to practice in a non-VA hospital environment is still in its infancy" (Maiocco et al., 2018, p. 5). As of 2019, Connecticut is the only other state mandating similar education, once every 6 years ("Continuing Education Requirements for Nurses by State," 2019).

In a mixed methods study of home care nurses, lack of knowledge of resources available to veterans, war-specific exposures, and veteran-specific health issues were identified practice gaps (Elliott, 2018). Of the 102 subjects in the study, about 50\% reported that they screened for military status, and only $18 \%$ felt confident in knowing how to make a referral to the VA. This demonstrates that while some nurses are screening for veteran status, they often do not know what to do with the information once obtained. However, home care nurses were able to identify a number of differences in caring for veterans compared to non-veterans (Elliott, 2019). Major themes from the study were: challenges coordinating care, building rapport takes more time, and recognizing the impact of military service on patient's worldview. This supports that this population does have healthcare needs that are different from other cultures within the United States and that this culture should be included in discussions related to cultural competency. In addition, nurses caring for veterans who utilize both VA and another healthcare system should be alert to medication overlapping (Chui et al., 2018), adherence (Taber et al., 2019), and overall coordination of medication regimens.

Bonzanto et al. (2019) conducted a study to examine the capacity of RNs working in non-VA settings to deliver appropriate culturally competent care to military, veterans, and their families. The researchers used a modified Ready to Serve survey (Cronbach's $\alpha=0.9081$ for the study) to survey nurses within a large multi-hospital system. Factor analysis revealed four factors: (a) knowledge, awareness, and attitudes about military culture; (b) practice behaviors, skills, and comfort; (c) health-related screening behaviors; and (d) beliefs about evidence-based practice. Bonzanto et al. (2019) reported 612 nurses participated out of 6,875 invited (response rate 9\%). The overall results of the study revealed few nurses employed at one of the hospitals within the health system possessed the cultural competency to care for military, veterans, and their families. Almost $70 \%$ said they never or seldom assess for military or veteran status (Bonzanto et al., 2019). Approximately $80 \%$ were unfamiliar with services available to assist with readjustment after military service, or with DoD and VA resources to assist clinicians in caring for those with mental health issues. From a competency perspective, only 25 (4\%) of respondents achieved a score of high cultural competence. However, it should be known that 10 of the 25 previously served in the military, 22 of the 25 had family who served, and 10 reported previous experience working in a military or veteran setting (Bonzanto et al., 2019).

Lastly, Vest et al. (2019) conducted a study of non-VA primary care physicians, PAs, and NPs to assess their barriers to providing care to veterans, the training providers perceived as most useful, and the tools and translational processes deemed to be adequate in enhancing cultural competency. Data analysis revealed three themes from the interviews, which were barriers to caring for patients who are identified as 
veterans, thoughts on tools that might help better identify and screen veteran patients, and thoughts on translating and implementing new care processes for veteran patients into everyday practice. Barriers included lack of knowledge on the impact military service has on a veteran and how that could change the provision of care, inconsistent knowledge of military culture/population, limited knowledge of resources and support services available in the community, and lack of coordination with the VA healthcare system (Vest et al., 2019). Although only one NP was included in the sample, study results related to challenges coordinating care with the VA were similar to Elliott's (2019) findings of home care nurses.

As the literature continues to expand related to care of the military/veteran population, targeted education of nurses will be needed. A critical first step is determining what health professionals' attitudes and views are in caring for this population. Knopf-Amelung et al. (2018) developed a tool to evaluate health professionals' attitudes toward veterans. Their Health Professionals' Attitude Toward Veterans (HPATV) scale measures three domains: culture, care, and health. The researchers state the tool could be utilized to conduct a needs assessment of health professionals in any setting to identify strengths and weaknesses that can inform professional development activities, or policy and procedure (Knopf-Amelung et al., 2018). Further, the HPATV can be used for program evaluation of veteranspecific education initiatives. Brommelsiek et al. (2018) used the scale to evaluate students' attitudes after completing an interdisciplinary course on military culture and found significant improvement in attitude across all domains of the HPATV. In addition, the researchers found a significant improvement in knowledge pre and post course.

\section{Patient-Centered and Culturally Competent Care}

The essentials of nursing practice at all levels mandate cultural competency as part of the nursing curricula (AACN, 2006, 2008, 2011). In making a case for veteran-specific content in nursing education, nurses and nurse educators need to recognize that this is ethically the right thing to do. As societal demographics change, nursing education must also change. To provide perspective to the need for change, consider how much time is spent in current nursing curricula focusing on the care of children newborn to age 5. According to the latest population estimates there are approximately 23 million children from birth to age of 5 in the United States ("POP1 Child Population," n.d.), just three million more than current military and veterans. Yet, curricular changes to include veteran-centered content seem sporadic and appear to remain limited across nursing education (Elliott \& Patterson, 2017). In discussions of vulnerable populations, veterans are not always part of the conversation. Yet, many are at risk for homelessness or incarceration as a result of unresolved mental health issues and other complex factors (National Coalition for Homeless Veterans [NCHV], n.d.). According to the NCHV (n.d.), an estimated 40,000 veterans are homeless on any given night. This represents about $11 \%$ of the adult homeless population. Demographic and social trends within the United States must be regularly reviewed and considered in curricular changes so nursing students are best prepared for a culturally sensitive practice in today's environment (Elliott \& Patterson, 2017).

A small number of studies have examined military, veterans, and family members' perspectives on healthcare. Butler et al. (2015) found that veterans universally wanted care that demonstrated the importance of respect for personhood, "the belief that veterans were deserving of care that recognized them as individuals with a unique (military) identity, life history, and experience, and worthy of respect no matter who they were or how successfully they had managed their lives" (p. 119). Veterans described caring behaviors of healthcare providers as communicating effectively, following up to ensure the veteran got what they needed, and using specialized knowledge about unique health issues veterans face (Cohen et al., 2018). Further, results indicated that veterans want providers to explain things to them, so it is clear what they need to do for themselves. Partnering and collaborating on healthcare (Cohen et al., 2018) and being direct in sharing information is important to veterans (Butler et al., 2015). A lack of understanding military culture (Borah \& Fina, 2017) or ability to speak military language (Cohen et al., 2018) 
may cause military service members, veterans, or family members to depart interactions in frustration. While many military service members and veterans may delay seeking healthcare for various reasons, the "need to be listened to and be treated with respect when they seek healthcare" overrides all other actions (Nworah et al., 2018, p. 775).

Worthy of highlighting is that, as a result of injury or exposure to traumatic events during military service, some service members or veterans may present to healthcare providers with symptoms which may be misunderstood or as if the person is behaving in a rude manner. Veterans voiced the importance for healthcare providers to recognize and be sensitive to difficult patients with a military history, and to be able to de-escalate situations because that is "what we need" (Butler et al., 2015, p. 122). Further, providers should be aware of the influence of the military ethos to be strong and stoical, as veterans tend to underreport or complain very little until something is seriously wrong. In a study of homeless male veterans, data supported veterans who utilize emergency departments instead of primary care do so because they have expressed they feel they have no other option (Weber et al., 2019). Recognizing that some providers go above and beyond to help and be an advocate, veterans in the study more often shared that not feeling valued and lack of voice when seeking care made them feel "disposable" (Weber et al., 2019, p. 5). Also important in caring for veterans is not to assume everyone has PTSD (Borah \& Fina, 2017).

\section{IMPLICATIONS FOR NURSING EDUCATION AND PRACTICE}

Across the literature and related disciplines, there is ample support demanding that civilian providers become more culturally sensitive and competent to provide the best patient-centered care to military and veteran populations, including their families. This same level of competency is necessary of faculty teaching veteran-centered content or teaching students who are veterans (Carlson, 2016). While there may be gaps in essential knowledge for currently practicing nurses and healthcare providers, this trend needs to change. Military service members, veterans, and their families deserve quality care and, with the projections of needing significantly more long-term care for those veterans who have served since the Gulf War era, nurses and nurse educators need to prepare themselves. Preparation begins during prelicensure nursing education.

Carlson (2016) conducted a study of six VANA faculty that produced five thematic concepts and dimensions related to veteran care for faculty competencies and four essential knowledge concepts and dimensions necessary to teach nursing students to provide quality care. Carlson (2016) stressed that cultural competence develops over time and with exposure to the population. A desire to learn and understand more about military service members, veterans, and their families is the first step. To do this, a nurse educator (or any nurse) must understand the importance of always recognizing and acknowledging a veteran and be open to learn about military/veteran culture and their experiences. Appreciating contributions through military service demonstrates sensitivity and can facilitate trust building. Treating them with humanity, respect, and sincerity can also build trust, which is essential to providing care. Being open minded, using open and honest communication, and intentionally listening to veterans' concerns can also demonstrate the care and empathy necessary to build trust (Carlson, 2016). As important is recognizing that military culture is team oriented and the role it plays in engaging and caring for military and veteran patients. Findings from this study can also guide educators outside of academia.

Educators require essential knowledge related to military and veteran populations to teach students and nurses in practice, so quality patient-centered and culturally sensitive care can be achieved. Having a basic understanding of each of the services (Army, Navy, Air Force, Marine Corps, and Coast Guard), rank structures, and historical knowledge of health issues related to war eras is a starting point. Further, unique healthcare needs of this population as a result of their service, impact of service on families, veteran-specific issues across gender and lifespan, and resources available through 
the VA and other organizations can greatly enhance the nurse-patient relationship when caring for this population. Being able to understand just enough about their experiences can be sufficient for nurses in civilian settings to establish rapport with military and veteran patients. Even inquiring how someone would like to be addressed (first name, last name, or by rank) can demonstrate respect and caring (Butler et al., 2015; Carlson, 2016; Cohen et al., 2018). Creating a respectful environment can increase trust, open up communication, and ideally have a positive effect on follow-up care and health outcomes (Weber et al., 2019).

In order to reduce healthcare risks, contain costs of care, and manage long-term effects of injuries sustained during military service, intentional education is vital. Continuing education (CE) and quality improvement efforts are essential to begin making headway on the health issues facing this population. Chargualaf (2019) argues that "it is not enough to merely acknowledge that veteran care is important" (p. 9). Nurses must seek professional development related to care of this population, and clinical educators and managers must examine processes to improve assessment and identification of military status. This includes developing veteran-centered competencies as part of professional CE for practicing nurses (Chargualaf, 2019).

\section{Student Veterans in Nursing}

In light of over two dozen Veteran's Bachelor of Science in Nursing programs that have emerged since 2013, faculty must also recognize veterans as students and how their service experiences can influence the transition to nursing education (Patterson et al., 2019a) and the teaching-learning process (Patterson et al., 2019b; Elliott et al., 2019). Faculty must consider how certain injuries could manifest in the classroom or clinical setting, subsequently determining how they would handle the situation. Applying the same principles of cultural sensitivity and competence of patient-centered care to student-centered teaching is needed. Student veterans bring a wealth of experience to nursing education and maximizing their skills and leadership abilities can add value to the workforce (Patterson et al., 2019a, 2019b). Tapping into these strengths can have a positive impact on student veterans' health and well-being (Elliott et al., 2019).

\section{FUTURE RESEARCH PRIORITIES}

For nurse educators both inside and outside of academia, opportunity exists to evaluate nursing and healthcare providers' knowledge, skills, attitudes, comfort, and confidence in caring for military and veteran populations. Development and research on innovative methods in teaching veteran-centered care as well as developing competency are needed. More empirical research is needed on best practices to bridge the gaps between military culture and civilian healthcare settings. Broadly, another look at the impact of Joining Forces and what nursing programs are doing to teach future nurses to care for military/veteran populations would help to inform all programs and keep the momentum going.

\section{CONCLUSIONS}

Improving veteran healthcare as a national priority, appreciating that nurses can create the greatest impact toward improving veteran health, is the right course of action. While this book is based primarily on research and experiences of U.S. military, veterans, and their families, the content can be transferred to similar populations across the globe. A number of national organizations have put forth efforts to promote the health and well-being of military, veterans, and their families. However, there is more to be accomplished to improve the healthcare for this population. Nurses and nurse educators have the ability and power to increase awareness within the nursing profession, so that veteran-centered care can be achieved. 


\section{REFERENCES}

The complete reference list for this chapter appears in the digital version of the chapter, accessible at https://connect.springerpub.com/content/book/978-0-8261-3597-1/chapter/ch01

\section{RESOURCES}

\section{Educational Resources}

AACN - Enhancing Veterans' Care Faculty Tool Kit www.aacnnursing.org/Teaching-Resources/Tool-Kits/Veterans-Care

NLN - Advancing Care Excellence for Veterans www.nln.org/professional-development-programs/teaching-resources/veterans-ace-v RAND - Veterans Health Care www.rand.org/topics/veterans-health-care.html WHV - ELNEC - For Veterans Updated Curriculum www.wehonorveterans.org/elnec-for-veterans-curriculum WHV - Free Webinars www.wehonorveterans.org/blog/resource_type/webinar

\section{Military Families}

Elizabeth Dole Foundation www.elizabethdolefoundation.org/ National Military Family Association www.militaryfamily.org/ RAND - Military Caregivers www.rand.org/topics/military-caregivers.html

\section{Post-Bachelors Veteran Health Education}

Drexel University - Service to Veterans Certificate www.drexel.edu/cnhp/academics/post-baccalaureate/certificate-pb-veterans-healthcare University of Colorado - Veteran and Military Health Care Specialty www.ucdenver.edu/academics/colleges/nursing/programs-admissions/graduate-programs/graduatespecialties/Pages/veteran-military-health-care.aspx 